\title{
REDUCING THE UNCERTAINTY IN A MEASURE OF THE ACCELERATION OF GRAVITY FOR THE ELECTRONIC KILOGRAM
}

\author{
B. Parker* and R. L. Steiner \\ National Institute of Standards and Technology ${ }^{+}$ \\ Gaithersburg, MD
}

\begin{abstract}
$\underline{\text { Abstract }}$
Calculating the force on a reference mass for the electronic kilogram experiment requires using both absolute and relative gravity meters to measure the acceleration of gravity. Tests have been conducted to achieve an uncertainty of less than 1 part in $10^{8}$.

\section{Introduction}

The watt balance technique [1] measures the relation of atomic clock time, laser length, Josephson voltage, quantum Hall resistance, and the Planck constant $h$ to artifact mass. This is done by balancing a mass with an induction coil in a magnetic field and measuring the force/current $F / I$ ratio, and then moving the coil and measuring the voltage/velocity $U / v$ ratio. The complete relation is

$$
(m g v) /\left(U^{2} / Z\right)\left(1 / K_{J-90}^{2} R_{K-90}\right)=h / 4
$$

where $m$ is a mass reference, $Z$ is a resistance reference, $g$ is the acceleration of gravity, $K_{\mathrm{J}-90}$ is the Josephson constant, and $R_{\mathrm{K}-90}$ is the von Klitzing constant.

The goal is to reduce the uncertainty to 10 parts per billion or less for the local acceleration of gravity $g$. An absolute gravimeter was used to measure gravity at the site of a United States Geological Survey (USGS) marker on the first floor of the laboratory housing the electronic kilogram experiment. A relative gravity meter was used to measure various gradients and obtain a transfer to a level about $5 \mathrm{~m}$ above and $4 \mathrm{~m}$ away from the USGS site.

\section{Measurement of Local Gravity}

The free-air gradient is the change in gravity with

\footnotetext{
*Currently Massachusetts Institute of Technology ${ }^{+}$Quantum Electrical Metrology Division, Electronics and Electrical Engineering Laboratory, U.S. Department of Commerce. Official contribution of the National Institute of Standards and Technology, not subject to copyright in the United States.
}

respect to the change in elevation and is nominally $-30.86 \mu \mathrm{m} / \mathrm{s}^{2}-\mathrm{cm}[2]$. The local value of this gradient next to the absolute gravimeter is needed to extrapolate its measured gravity value down to the floor. It is also needed to provide the reference value for the height of the transfer meter near the absolute gravimeter. Another gradient value is needed inside the watt balance at the level of the test mass. A gravity transfer between those two locations (downstairs by the gravity standard mark and upstairs in the watt balance) is needed to establish a gravity value point near the reference mass.

Various transfer tests were conducted in February 2007 , in part to make the measurement, but also to gain experience in using the meter. Several tests were conducted. These included a gravity map of the area around both the USGS marker and the watt balance, and measurements made with the vacuum chamber (about $500 \mathrm{~kg}$ ) both raised and lowered. The absolute gravimeter has produced values over several years. This paper will expand on various problems encountered.

\section{$\underline{\text { Results }}$}

The first floor gradient was $-31.49 \pm 0.66 \mu \mathrm{m} / \mathrm{s}^{2}-\mathrm{cm}$, the second floor gradient $-31.79 \pm 0.27 \mu \mathrm{m} / \mathrm{s}^{2}-\mathrm{cm}$. A transfer value of $15.56 \pm 0.02 \mathrm{~mm} / \mathrm{s}^{2}$ was measured. For the transfer measurements, a combined relative standard uncertainty is estimated at $0.0063 \mu \mathrm{W} / \mathrm{W}$ (units equivalent contribution to the watt value). Later in July, a 2-week series of absolute measurements using the g-meter resulted in a value of $9.80103229 \mathrm{~m} / \mathrm{s}^{2}$ with a combined relative standard uncertainty of $0.0056 \mu \mathrm{W} / \mathrm{W}$. A combined uncertainty of $0.0084 \mu \mathrm{W} / \mathrm{W}$ would apply to the calculated $g$ value at the mass level.

\section{$\underline{\text { References }}$}

[1] B. P. Kibble, Atomic Masses and Fundamental Constants, vol. 5, J.H. Sanders and A.H. Wapstra, Ed. New York: Plenum, p. 545, 1976.

[2] W. Lowrie, Fundamentals of Geophysics, Cambridge University Press, 1997. 
